\title{
Ecological footprint forecasts face sceptical challenge
}

\section{Natasha McDowell, London}

The concept of the 'ecological footprint' the area of productive land and water that people need to support their consumption and to dispose of waste - is very much in vogue. London's footprint is 120 times as big as the land it covers, according to one wellpublicized estimate; Hong Kong's may be 444 times so. And according to a report from the World Wide Fund for Nature (WWF), Earth's ecological footprint is in danger of growing larger than the entire planet.

But a report by the Danish Environmental Assessment Institute in Copenhagen now run by environmental-policy specialist Bjorn Lomborg - has questioned the usefulness of the footprints as a research tool.

In his 2001 book The Skeptical Environmentalist, Lomborg used statistics to challenge widely held beliefs about the environment, and was criticized by many environmental scientists (see Nature 414, 149-150; 2001). His new report, Assessing the Ecological Footprint, released in August, claims that footprints are a weak analytical tool and are highly sensitive to changes in calculation method. "There is no 'correct' ecological footprint," Lomborg's team says.

In its Living Planet Report 2002, for example, the WWF claims that we will need between 1.8 and 2.2 Earth-sized planets to meet our needs by 2050. But Lomborg's team points out that this ignores the possible growth in the use of renewable resources. If, as many believe, the use of such resources increases, the 2050 footprint would not be so large. Lomborg also repeats a point made by some environmentalists - that ecological footprints provide snapshots of current resource use, but should not be used to generate predictions about the future. "It is a good effort, but the ecological footprint approach doesn't work right now," says Lomborg.

But many researchers say that the measure

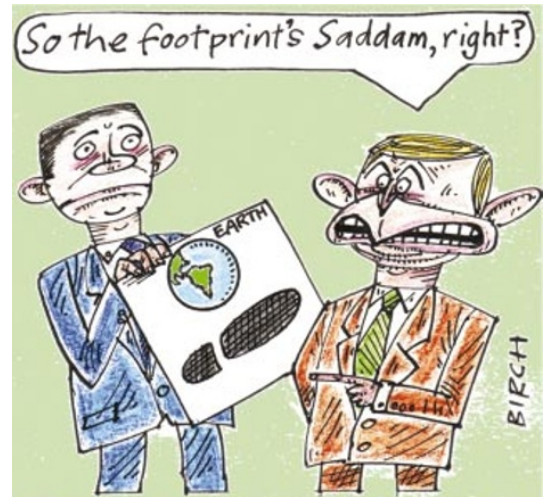

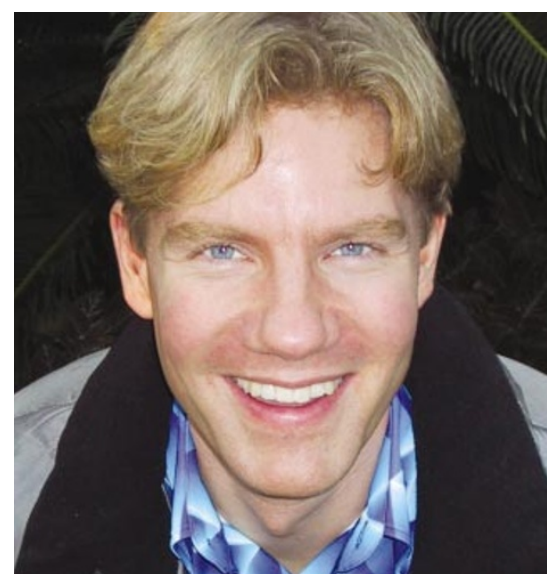

Tread carefully: Bjorn Lomborg says that there are many ways to calculate ecological footprints.

is useful. Advocates argue that footprints help to summarize information, and are no more of a gimmick than such well-accepted yardsticks as gross domestic product. "No single indicator is a good measure, as every time you collapse lots of diverse information you lose something," says Simon Levin, an ecologist at Princeton University in New Jersey. "But they are useful, in the same way as indicators helping people judge the state of the economy are."

Robert Watson, chief scientist at the World Bank, admits that footprints cannotbe used as predictive tools, but says that they can help to weigh up different options, provided that the underlying assumptions are made clear. "It is perfectly valid to ask what the result of continuing to produce energy using predominantly fossil fuels will be," Watson says. "But we must then ask what the footprint will be if we have a different way of producing energy." If we don't make the shift to renewable energy sources, for example, the WWF's model may end up being accurate, he says.

Watson is also co-chair of the Millennium Ecosystem Assessment, a four-year effort to survey the health of the world's ecosystems (see Nature 417, 112-113; 2002). Footprints may yet be included as part of the assessment. "We will examine the approach to see how useful it is and to what degree it is a quantitative concept," Watson says.

Researchers who have criticized the use of ecological footprints say that Lomborg has exaggerated their views. Ian Moffat, an ecologist at the University of Stirling, UK, is quoted in the institute's report as arguing that the concept is "nothing more than an important attention-grabbing device". But Moffat claims that Lomborg took his remarks out of context and that he regards footprints as valuable in showing the scale of ecological problems.

\section{Greenhouse gas that preserves ozone puts protocols at odds}

\section{Quirin Schiermeier, Munich}

A head-on collision between efforts to combat climate change and those aimed at protecting the ozone layer is on the cards when delegates from 146 nations meet in New Delhi next week to discuss greenhouse-gas emissions.

At issue are hydrofluorocarbons (HFCs), introduced to replace chlorofluorocarbons (CFCs) under the 1987 Montreal Protocol, the international agreement on protecting the ozone layer. But the Kyoto Protocol, which aims to limit greenhouse-gas emissions, warns against using HFCs, as they have a global-warming potential 1,300 times that of carbon dioxide.

HFCs, which are used in applications such as air-conditioning systems, currently account for less than $2 \%$ of global greenhouse-gas emissions. But according to a study published in June by the Brusselsbased Climate Action Network Europe (CAN Europe), growing markets for HFCs in developing countries are likely to lead to a tenfold increase in HFC emissions by 2050 . "There is a glaring contradiction between the two initiatives," says Jason Anderson, an energy-technology expert at CAN Europe.

At the New Delhi meeting, which starts on 23 October and is intended to discuss the implementation of the Kyoto Protocol, delegates may ask technical advisers to the two treaties to carry out a joint study of other CFC replacements. Hydrocarbon alternatives, such as isobutane and pentane, are already used in Europe and by a growing number of manufacturers in Japan and China.

But US industry uses HFCs - which, unlike the hydrocarbon alternatives, are not flammable. Developing countries also pose problems. They receive annual subsidies worth US\$150 million under the Montreal Protocol to convert their industries to ozonefriendly technologies. In most cases, this is used for the relatively cheap switch to HFCs. Opting for a technology tends to cement its use for many years, says Stephan Sicars, a member of the Technology and Economic Assessment Panel of the Montreal Protocol.

The CAN study criticizes this switch. "Using subsidies to switch to HFCs is a lost opportunity," says Anderson. "It also makes developing countries vulnerable to future greenhouse-gas-reduction requirements." Like many experts, he believes the lack of explicit links between the two protocols lies at the heart of the problem. "The technical study can help open people's eyes," he says. "But without a firm policy commitment, it won't solve the principal dilemma." 